\title{
Psychiatric clinics in probation offices in South Wales
}

\author{
Phil Huckle, Tara Travier and Sylvia Scarf
}

\begin{abstract}
A descriptive study of a poychiaticic probation clinic based in South Woles is presented. Over a three year period, 100 probation clients were cassesesed by forensic peychiatitsts of the request of the Probation Services in South Woises. The majortly of these clients were mentally clisordered, with common diconoces being personatity clisorder (35\%), subetance misuse (11\%), schizophrenla (10\%) and post-traumatic stress disorder (9\%). The nonattendence rates for these clients was $0 \%$ for the first and 13.3\% for subequent cppointments. Psychicitic probalion clinics seom to be anciogous to general poychicitic clinics based in Pilmary Core.
\end{abstract}

The Probation Service has a key role in both the assessment and management of mentally disordered offenders. Research indicates that approximately one-fifth of probation clients have been estimated to have some form of mental disorder (Pritchard et al, 1992).

Home Office circular 66/90, and more pertinently in Wales the Report of All Wales Advisory Group on Forensic Psychiatry (Welsh Office, 1992), stress the importance of close liaison being developed by all agencies involved with mentally disordered offenders. The Psychiatric Probation clinic described is one attempt at inter-agency cooperation in practice. It should be noted that this is an attempt by a tertiary NHS unit to work within the criminal justice field and is additional to any contact or arrangements already in place by the Probation Service with local hospital or community mental health services.

The South Wales Forensic Psychiatric Service is based at the Caswell Clinic in Bridgend. Referrals are accepted from a variety of sources including health, social services and the criminal justice system. In 1992, the senior registrar in forensic psychiatry offered regular sessions at probation offices throughout South Wales. The sessions took place in offices in both rural and urban areas within a 50 mile radius of the Caswell Clinic. Referrals were made either directly by the probation officers or indirectly by the probation liaison officer to the Caswell Clinic. The purpose of the clinics was to provide open access for psychiatric assessment as well as providing a consultation service for probation officers regard- ing the management of their clients with mental health problems.

\section{The study}

The 100 probation clients referred to the service during a three year period from April 1992 to April 1995 are described. The data collected included age, gender, current offence, reason for referral, psychiatric history, psychiatric diagnosis and outcome of assessment.

\section{Findings}

Of the 100 clients referred, 92 were male and eight female. Fifty-eight per cent were seen presentence and $42 \%$ post-sentence. Reasons for the assessment were to assess the clients mental state $(30 \%)$; to assess their suitability for treatment (15\%); for advice regarding their management (25\%), and for the preparation of a court report (30\%).

The ages of the probation clients referred ranged from 18-77 years and the mean age was 31.4 years. Forty-nine per cent of the probation clients referred had a previous psychiatric history (defined as either in- or out-patient treatment). Sixty-seven per cent were single, $12 \%$ married, $9 \%$ divorced, $3 \%$ were separated and $7 \%$ cohabiting.

The clinical diagnosis of the probation clients referred made at assessment were: personality disorder (35\%); schizophrenia (10\%); substance misuse (11\%): post-traumatic stress disorder (9\%): affective disorder (6\%), and learning diffculties (7\%).

The majority of the offences committed by the clients were minor, however, some (23\%) had committed serious sexual or violent offences.

A range of interventions were offered to the clients, including individual cognitive and psychodynamic therapy, psychotropic medication. grief counselling and alcohol/drug counselling. Three cases were admitted to hospital and a further three to District Psychiatric Services. Thirty-one per cent were offered out-patient psychiatric treatment as a condition of a probation order. These clients comprised 27 men and 
four women. Seventeen out of the 31 successfully completed the order and have since been discharged; the other 14 are still subject to an order. Of the 31 probations treated on a psychiatric probation order, only seven $(22 \%)$ have reoffended during a follow-up period which ranges from two months to three years. With regard to attendance at the psychiatric probation clinic, all clients referred attended their first appointment, but $13.3 \%$ did not attend for subsequent appointments.

\section{Comments}

Psychiatric clinics based in probation offices have been described previously. Collins et al (1993) described a weekly clinic based in the north of England over a two-year period. In their study, 45 new cases were seen in total, although the majority were seen on more than one occasion. The usual reason for referral was a request for an assessment of a client's mental state, including dangerousness. The majority of those referred were young; their offences were in the lower end of the spectrum of seriousness (assault, acquisitive, motoring and public order offences) but also included more serious matters. In their study $50 \%$ had a previous psychiatric history. The diagnoses made at assessment included: personality disorder (38\%); substance dependency $(20 \%)$, and chronic psychosis (15\%). Our survey of the South Wales psychiatric probation clinics found a similar profile of the probation clients who are referred.

Psychiatric probation clinics have been criticised because relatively few clients are referred (Bowden, 1978). The probation clients in our survey found the setting of the clinics acceptable to them and found it easier to disclose personal information in a setting to which they were accustomed. This may partly explain the low levels of non-attendance described earlier and compares favourably with a non-attendance rate of $17.5 \%$ in a general psychiatric clinic (Thapar \& Ghosh, 1991) and 33\% in a forensic psychiatric clinic based in a hospital setting (Bowden, 1978).

Thirty-one per cent of the probation clients in our survey were treated as a requirement of a probation order, the so-called 'psychiatric probation order'. This arrangement is described in the Powers of the Criminal Court Act 1973 and allows an offender who does not need to be detained in hospital but who is suffering from a mental disorder which can be treated to have the said treatment. The following types of treatment are identified in the Act: treatment as a resident patient in a psychiatric hospital; treatment as a non-resident patient; treatment by or under the direction of such duly qualified medical practitioner (Section 12 of the Mental Health Act England \& Wales, 1983) as may be specified.

The order is made after a court has recetved written or oral evidence from an approved medical practitioner and the offender is willing for such an order to be made. The report records as implications for probation management that it should establish co-working agreements at all levels between local health authorities and the probation service.

A recent survey of the use of the psychiatric probation order (HM Inspectorate of Probation, 1993) suggested that the use of such an order is decreasing in some areas and that different regions have different rates of use. Lewis (1980) followed up 118 psychiatric probation order cases in the Nottinghamshire area. The majority of these cases were young and the mental disorders were usually depression, personality disorder or addiction.

In our survey the psychiatric probation order proved a useful way of accessing appropriate health care for people who were at serious risk of a custodial sentence, and psychiatric clinics based in probation offices were deemed to be a success as far as the probation staff and clients were concerned.

\section{References}

BOwDEN, P. (1978) A psychiatric clinic in a probation office. British Joumal of Psychiatry, 138, 448-451.

Coluns, P., BALl, H. \& Costelo, A. (1993) The psychiatric probation clinic. Psychiatric Bulletin. 17, 145-146.

HM INSPECTORATE OF PROBATION (1993) Probation Orders with Requirements for Psychiatric Treatment-Report of a Thematic Inspection. London: Home Office.

HOME OfFice (1990) Provision for Mentally Disordered Offenders. Home Office Circular No. 66/90.

Lewis, P. (1980) Psychiatric Probation Orders: Roles and Expectations of Probation Officers and Psychiatrists. Cambridge: Institute of Criminology. University of Cambridge.

Prtrchard, C., Cotton, A., Godson, D., et al (1992) Menta illness, drug and alcohol abuse and HIV risk behaviour in 214 young adult probation clients. Soctal Work and Soctal Sciences Review, 3, 227-242.

THAPAR, A. \& GHOSH, A. (1991) Non-attendance at a psychiatric clinic. Psychiatric Bulletin. 16, 205-206.

WeLSH OFFICE (1992) Report of the All-Wales Advisory Group on Forensic Psychiatry. Wales: Welsh Office.

*Phil Huckle, Senior Registrar in Forensic Psychiatry: Tara Travier, Psychology Student; and Sylvia Scarf, Senior Probation Liaison Officer, South Wales Forensic Psychiatric Service \& Mid Glamorgan Probation Service

*Correspondence: Dr Phil Huckle. The South Wales Forensic Psychiatric Service, The Caswell Clinic. Glanrhyd Hospital, Bridgend, Mid Glamorgan CF31 4LN 